\title{
Epidemio-Clinical, Therapeutic and Evolutive Aspects of Pulmonary Embolism in Young Subject in the Cardiology Department in Point “G” Hospital University Center Bamako
}

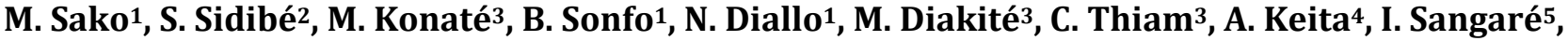 \\ H. O. Ba ${ }^{5}$, Y. Camara ${ }^{3}$, L. Bouaré1, Y. R. Koumaré1, S. Coulibaly'1, I. Minta ${ }^{5}$ \\ ${ }^{1}$ Cardiology Department, Point “G” Hospital University Center, Bamako, Mali \\ ${ }^{2}$ Cardiology Department, Hospital MALI, Bamako, Mali \\ ${ }^{3}$ Cardiology Department, Hospital KATI, Bamako, Mali \\ ${ }^{4}$ Cardiology Department, Hospital LUXEMBOURG, Bamako, Mali \\ ${ }^{5}$ Cardiology Department, Gabriel TOURE Hospital University Center, Bamako, Mali \\ Email: koumareyvesroland@gmail.com
}

How to cite this paper: Sako, M., Sidibé, S., Konaté, M., Sonfo, B., Diallo, N., Diakité, M., Thiam, C., Keita, A., Sangaré, I., Ba, H.O., Camara, Y., Bouaré, L., Koumaré, Y.R., Coulibaly, S. and Minta, I. (2020) Epidemio-Clinical, Therapeutic and Evolutive Aspects of Pulmonary Embolism in Young Subject in the Cardiology Department in Point "G" Hospital University Center Bamako. Open Journal of Epidemiology, 10, 393-398.

https://doi.org/10.4236/ojepi.2020.104031

Received: August 27, 2020

Accepted: October 20, 2020

Published: October 23, 2020

Copyright $\odot 2020$ by author(s) and Scientific Research Publishing Inc. This work is licensed under the Creative Commons Attribution International License (CC BY 4.0).

http://creativecommons.org/licenses/by/4.0/ (c) (i) Open Access

\begin{abstract}
Objective: The purpose of this work was to determine the epidemiological, clinical and evolutionary aspects of the pulmonary embolism of the young person in the cardiology department of the University Hospital Center (CHU) Point G in Bamako-Mali. Methodology: This was an analytical study from January 01, 2018 to December 31, 2018 in the CHU Point G cardiology department, including all patients hospitalized during this period. Results: Of 1379 hospitalized patients, 19 patients were concerned by pulmonary embolism of the young person. The prevalence of pulmonary embolism of the young person was $1.37 \%$. The most affected age group was $21-30(47.4 \%)$ of patients. The predominance was female $(89.47 \%)$ with a gender ratio of 0.11 in favour of women. The average age in the series was 29.79 years with extremes of 16 years and 40 years. Factors predisposing to pulmonary embolism were dominated by peri partum, cardiomyopathy and obesity with $47.3 \%$, $31.57 \%$ and $21.1 \%$, respectively. The dominant signs were chest pain and dyspnea in $94.7 \%$ and $89.5 \%$ of cases respectively. Pulmonary embolism was unlikely in $60.52 \%$ according to the Geneva and Wells score simplified. At the thoracic angioscanner, the embolism was bilateral in $52.6 \%$ of cases and distal in $36.8 \%$ of patients; in 10 patients who performed cardiac ultrasound, pulmonary arterial hypertension (70\%), dilation of the right ventricle $(20 \%)$ and left ventricular dilation (40\%). Hyper leucocytosis (47.4\%), anemia and low prothrombin rate (TP) $(22.2 \%)$ were the most found biological abnormalities.
\end{abstract}


More than $2 / 3$ (68.5\%) our patients had an intermediate mortality risk according to the PESI (Pulmonary Embolism Severity Index) score. The average hospital stay was 10 days. Hospital mortality was $10.5 \%$. Conclusion: The pulmonary embolism of the young person is a frequent, serious and multifactorial pathology and the female sex is most affected especially during peri partum periods, hence the need for preventive measures. Clinical signs are not specific and based on the assessment of clinical probability. Pulmonary angioscanner remains the confirmation review in our context.

\section{Keywords}

Pulmonary Embolism, Young Subject 15 - 40 Years, Cardiology, Point G Hospital

\section{Introduction}

Pulmonary embolism, defined by the obliteration of the pulmonary artery or one of its branches by a circulating foreign body, remains a serious, frequent and difficult to diagnose pathology. In France, it affects $17 \%$ to $42.6 \%$ of hospitalized patients and appears in $8 \%$ to $52 \%$ of post-mortem examinations [1] [2] [3]. In Africa, classically rare pulmonary embolism [4] [5] [6] [7] constitutes $0.1 \%$ of nosological groups in specialized cardiological settings in Nigeria and $3.8 \%$ of cardiovascular manifestations during HIV infection in Burkina Faso [8] [9]. Its prognosis is horrible because it is responsible in France for 1000 to 20,000 annual deaths and is the third leading cause of death in the USA [10] [11] [12]. In Mali in 2011 the hospital prevalence of pulmonary embolism was 1.7\% [13]. This work aimed to determine the hospital prevalence of pulmonary embolism in young subjects and to identify the epidemiological, clinical and evolutionary aspects in the cardiology department of the Point G University Hospital.

\section{Materials et Méthodes}

This was a prospective and analytical study carried out in the cardiology department of the CHU Point G from January 01, 2018 to December 31, 2018 and concerned all patients hospitalized during the study period.

The inclusion criteria were young patients aged 15 to 40 years, both sexes hospitalized in the so-called ward for pulmonary embolism confirmed by pulmonary angioscanner during the study period.

The exclusion criteria were:

Young patients hospitalized on suspicion of pulmonary embolism but not performing pulmonary angioscanner.

Confirmed pulmonary embolism in patients over 40 years of age.

\section{Data collection:}

Patients were recruited from the hospitalization file. The parameters studied in this file were sociodemographic data, clinical discovery circumstances, NFS 
results, D-dimers, fasting blood sugar, creatininemia, blood ionogram and pulmonary angioscanner. Word and Excel 2013 software was used for data entry and SPSS 16.0 and Epi Info 3.3.2 software for analysis. The static test used was the ki2 with a $5 \%$ meaning threshold.

\section{Results}

During the study period, out of 1379 patients admitted, 19 patients were for pulmonary embolism in young subjects, ie a hospital prevalence of $1.37 \%$. The predominance was female $(89.50 \%)$ (Table 1 ) with a sex ratio of 0.11 in favor of women. The most affected age group was 21 - 30 years, or $47.4 \%$ (Table 1). The average age was 29.79 years with extremes of 16 and 40 . The predisposing factors for pulmonary embolism were dominated by peri partum, cardiomyopathies and obesity with $47.3 \%, 31.57 \%$ and $21.1 \%$, respectively (Table 2 ). The reasons for consultation were chest pain and dyspnea in $94.7 \%$ and $89.5 \%$ respectively. An oxygen desaturation of less than $90 \%$ was observed in $41.1 \%$ of patients. Blood pressure was normal in the majority of cases (94.8\%). Thrombophlebitis was observed in $36.8 \%$ and signs of right ventricular failure in $26.3 \%$ of patients. Pulmonary embolism was unlikely in the majority, $60.52 \%$ according to the Geneva and Wells simplified score. D-dimers in all patients were positive (100\%), troponin elevated in $5.26 \%$ of cases. On the electrocardiogram, the rhythm was most often sinus (94.7\%) and tachycardia in $84.2 \%$; right atrial hypertrophy (47.4\%) and S1Q3 appearance in $42.1 \%$ of cases On chest angiography embolism was bilateral in $52.6 \%$ of cases (Table 3 ) and distal in $36.8 \%$ of patients. In 10 patients who performed the cardiac ultrasound, pulmonary arterial hypertension $(70 \%)$, dilation of the right ventricle (20\%), dilation of the left ventricle $(40 \%)$, segmental akinesia (20\%) and LVEF were noted. lowered in 30\% of cases. $\%$. Hyper leukocytosis (47.4\%), anemia and low PT (22.2\%) were the most common laboratory abnormalities. More than $2 / 3$ (68.5\%) of our patients had an intermediate risk of mortality according to the PESI score. All patients in the sample will receive anticoagulant therapy combined with oxygen therapy, diuretics and ACE inhibitors in complicated forms. Due to lack of local availability, no patient will benefit from fibrinolytic treatment and also in the absence of a cardiovascular surgery unit in Bamako no case of embolectomy has been performed. The outcome was favorable without complications in $78.9 \%$ of patients. The average hospital stay was 10 days. Hospital mortality was $10.5 \%$.

Table 1. Distribution of patients according to their age and sex.

\begin{tabular}{clllllr}
\hline Age range & \multicolumn{2}{c}{ Female } & \multicolumn{2}{c}{ Male } & \multicolumn{2}{c}{ Total } \\
\hline & Quantity & $\%$ & Quantity & $\%$ & Quantity & $\%$ \\
$15-20$ ans & 02 & 10.50 & 00 & 00 & 02 & 10.50 \\
$21-30$ ans & 09 & 47.40 & 00 & 00 & 09 & 47.40 \\
$31-40$ ans & 06 & 31.60 & 02 & 10.50 & 08 & 42.10 \\
TOTAL & 17 & 89.50 & 02 & 10.50 & 19 & 100.0 \\
\hline
\end{tabular}


Table 2. Distribution of patients according to their predisposing factors to EP.

\begin{tabular}{ccc}
\hline Factors predisposing MTVE & Quantity & Percentage \% \\
\hline Peri partum & 09 & 47.30 \\
Cardiomyopathy & 06 & 31.57 \\
Obesity & 04 & 21.10 \\
Cancer & 01 & 05.30 \\
Pelvic surgery & 01 & 05.30 \\
Ischemic stroke & 01 & 05.30 \\
ATCD MTVE & 01 & 05.30 \\
\hline
\end{tabular}

Table 3. Distribution of patients according to the result of their thoracic angiography.

\begin{tabular}{ccc}
\hline Obstruction of the AP & Quantity & Percentage \\
\hline Left branch & 06 & 31.6 \\
Right branch & 03 & 15.8 \\
Bilateral & 10 & 52.6 \\
\hline
\end{tabular}

\section{Discussion}

The prevalence of pulmonary embolism in the study was $1.37 \%$ compared to $3.8 \%$ in NIGERIA [8] from the post-mortem series and as much in Burkina among cardiovascular manifestations during HIV infection [9]. This lower prevalence could be explained by the insufficient technical platform for the diagnostic approach and the nature of these studies, necropsy in Nigeria and on populations at risk in Burkina. In Europe, the prevalence of pulmonary embolism is higher varying between $17 \%-42.6 \%$ [1] [2]. The decline in prevalence in black compared to European series can be explained by the platelet hypoaggregability of black and its rapid fibrinolysis [13]. The average age was 29.79 years against $64 \pm 17$ years in France [1]. This difference could be explained by the absence of prophylactic anticoagulation in our deprived areas and also by the young age of our patients' heart. Regarding the sex, it was predominantly female (89.47\%) which is classic in the literature [14] and could be explained by the increased thromboembolic risk observed in women linked to the presence of some factors specific to them: pregnancy, childbirth, contraception ... The factors predisposing to pulmonary embolism were dominated by the peri partum and heart disease with respectively $47.30 \%$ and $31.57 \%$ comparable to that of KANE [15] which found $30.58 \%$ of heart disease. Oxygen desaturation was observed in $41.1 \%$ and signs of right ventricular failure in $26.3 \%$, indicating the severity of pulmonary embolism in these patients and delay in diagnosis. According to the Geneva and Wells simplified score, pulmonary embolism was unlikely in the majority, $60.52 \%$ compared to $40 \%$ in the literature [16]. We have seen in our short series the classic interest of the ECG (right atrial enlargement, an S1Q3 aspect and sinus rhythm and tachycardia). In 10 patients who per- 
formed the cardiac Doppler ultrasound, there was pulmonary arterial hypertension $(70 \%)$, dilation of the right ventricle (20\%), mainly indicative of the severity of the pulmonary embolism; dilation of the left ventricle (40\%), segmental akinesia (20\%) and lowered LVEF in 30\% of cases, even seen in KANE [15] and synonymous with an underlying heart disease. On thoracic CT angiography the embolism was bilateral in $52.6 \%$ of cases and distal in $36.8 \%$ of patients. Hyper leukocytosis (47.4\%), anemia and low PT (22.2\%) were the most common laboratory abnormalities; the inadequacy of the technical platform and lack of financial means were factors limiting biological exploration, in particular: SAPL, protein $\mathrm{C}$ and $\mathrm{S}$, thrombophilia, etc. All patients in the sample will receive anticoagulant therapy combined with oxygen therapy, diuretics and ACE inhibitors in complicated forms. Due to lack of local availability, no patient will benefit from fibrinolytic treatment and also in the absence of a cardiovascular surgery unit in Bamako no case of embolectomy has been performed. Moreover, this is an exceptional indication in thromboembolic disease and only experiences medical treatment failures. More than 2/3 (68.5\%) of our patients had an intermediate risk of mortality according to the PESI score. The hospital outcome was considered favorable in $78.9 \%$ of patients with remission of functional and physical signs and absence of complications. We recorded a lethality of $10.52 \%$ greater than the $5 \%$ in the literature [17]. According to the same sources in the absence of treatment the lethality varies between $25 \%-30 \%$. The high mortality rate in the study could be explained by the delay in admission of patients, the absence of prophylactic anticoagulation in peripartum, the high population of heart failure and also the absence of fibrinolytics in the arsenal therapeutic. The average hospital stay was 10 days compared to 12 days for KANE [15].

\section{Conclusion}

Pulmonary embolism remains horrible due to its mortality, progressive complications and the high cost of its prevention. Reducing its morbidity mortality and mortality requires prevention and prophylactic anticoagulation in the face of certain etiological factors. Pulmonary angiography remains the confirmatory diagnosis.

\section{Conflicts of Interest}

The authors declare no conflicts of interest regarding the publication of this paper.

\section{References}

[1] Palud, L., Laurent, M., Guéret, P., Meunier, C., Garin, E., Benoît, P.-O., Belléguic, C., Bernard du haut Cilly, F., Lmange, C.A. and Daubert, J.-C. (2004) Intérêt de l'association du dosage des D-Dimères et de l'évaluation de la probabilité clinique dans une stratégie diagnostique non invasive de l'embolie pulmonaire. Archives des maladies du cour et des vaisseaux, 97, 93-99.

[2] Barrelier, M.-T., Lezin, B., Landy, S. and Hello, C.L. (2001) Prévalence de la 
thrombose veineuse diagnostiquée par échographie doppler des membres inférieurs dans la suspicion d'embolie pulmonaire et de l'embolie pulmonaire confirmée. Journal des maladies Vasculaires Masson, 26, 23-30.

[3] Gold Haber, S.Z. (1985) Strategies for Diagnostic in Pulmonary Embolism and Deep Venous Thrombosis. W.B. Saunders CY, Philadelphia, 79-97.

[4] Awotedu, A.A., Igbokwe, E.O., Akang, E.E. and Aghadiuno, P.O. (1992) Pulmonary Embolism in Ibadan, Nigeria: Five Years Autopsy Report. Central African Journal of Medicine, 38, 432-435.

[5] Touze, J.E., Moncany, G., Amonkou, A., Cailleau, G., Monnier, A., Kacou, M. and Bertrand, E. (1985) Pulmonary Thromboembolic Diseases in Ivory Coast (Apropos of 13 Cases). Med Trop., 45, 43-46.

[6] Elegbeleye, O.O. and Femi-pearse, D. (1975) Pulmonary Embolism in Africans. Tropical and Geographical Medicine, 27, 31-33.

[7] Adebonojo, S.A., Abioye, A.A., Osinowo, O., Adebo, O.A. and Grillo, I.A. (1979) Pulmonary Embolism in Ibadan: A Clinico-Pathological Reappraisal. East African Medical Journal, 56, 580-588.

[8] IGUN (2001) A 10-Year Review of Venous Thrombo-Embolism in Surgical Patients Seen in Jos, Nigeria. Nigerian Postgraduate Medical Journal, 8, 69-73.

[9] Niakara, A., Drabo, Y.J. and Kambire, Y. (2002) Cardiovascular Diseases and HIV Infection: Study of 79 Cases at the National Hospital of Ouagadougou (Burkina Faso). Bulletin de la Société de Pathologie Exotique, 95, 23-26.

[10] Bell, W.R. (1982) Pulmonary Embolism: Progress and Problems. The American Journal of Medicine, 72, 181-183. https://doi.org/10.1016/0002-9343(82)90807-5

[11] Robin, E.D. (1977) Over Diagnosis and over Treatment of Pulmonary Embolism: The Emperor May Have No Clothes. Annals of Internal Medicine, 87, 775-781. https://doi.org/10.7326/0003-4819-87-6-775

[12] Ariel, C. (1997) Cardiologie et pathologies cardiovasculaire. Edition Estem. 593-711.

[13] Diall, I.B. (2011) Etiologie, clinique et évolution de l'embolie pulmonaire à propos de 30 cas à Bamako. Mali Médical, 26, 3-6.

[14] Barrelier, M.T., Lezin, B. and Landy, S. (2001) Prévalence de la thrombose veineuse diagnostiquée par échographie doppler des membres inférieurs dans la suspicion d'embolie pulmonaire et de l'embolie pulmonaire confirmée. Journal des Maladies Vasculaires, 26, 23-30.

[15] Kane, K. (2016) Maladie thromboembolique veineuse dans le service de cardiologie du CHU Point G. Thèse de médecine, Faculté de Médecine, de Pharmacie et d'odontostomatologie de Bamako, 50.

[16] Armand-Perroux, A. and Barrelier, M.-T. (2008) La thrombose veineuse: Quoi de neuf? Réanimation, 17, 736-744. https://doi.org/10.1016/j.reaurg.2008.09.014

[17] Moses, D.C., Silvert, T.M. and Bookstein, J.J. (1973) The Complementary Roles of Chest Radiography, Lung Scanning, and Selective Pulmonary Angiography in the Diagnosis of Pulmonary Embolism. Circulation, 47, 1-108.

https://doi.org/10.1161/01.CIR.49.1.179 